\title{
The Study of Problems and Applications of Communication Era in (Virtual) E-learning
}

\author{
Amin Ashir \\ The member of young \\ researchers club, Islamic Azad \\ University of \\ Dezful, Iran
}

\author{
Sedigheh Navaezadeh \\ Sama Technical and Vocational \\ Training College, Islamic Azad \\ University, Mahshahr, Branch \\ Mahshahr, Iran
}

\author{
Sara Ziagham \\ Department of Midwifery, Shushtar \\ Faculty of Medical Sciences, Ahvaz \\ Jundishapur University of Medical \\ Sciences, \\ Ahvaz, Iran
}

\begin{abstract}
We are in the era called information age. In this era, the role of information and communication is very important because the role of education and training through communication is very effective, and an electronic name has been assigned to the new type of training and learning changes including information gathering, processing and distributing. Interaction of electronic training and knowledge management continuously increases due to unavoidable convergence of these two technologies. In one side, a desired output is the result of learning knowledge integrated with practical skills and experiences. On the other side, if staffs have been trained as well as possible, and be ready for using knowledge, applying and associating it, then knowledge can be managed easily. With regard to benefits of e-learning and its abilities for training, it seems that its integration with current training programs at universities, where common training is provided through integration of traditional learning and e-learning, is unavoidable. This is noticeable in training field that has too many addresses with various interests, experiences and training needs and skills.
\end{abstract}

Keywords: Information era; E-learning, Knowledge management; Learning knowledge; traditional learning and training

\section{INTRODUCTION}

E-learning, as an achievement of scholars in science and philosophy fields, is a response to new information requirements, human training in information society. Changing human knowledge paradigm in $20^{\text {th }}$ century and moving from possibility of accessing certain knowledge about the world toward recognition uncertainty is noticeable in technology level. These changes occurring in technology level moved the route of technology development from those technologies that increased human power in mass industrial productions toward those technologies that reinforced thinking power (such as processing, analysis, evaluation and etc.). as an example, ecommerce (in business) and e-learning (in the field of knowledge management) have emerged.

Using information technology in training field requires local standards setting and interdisciplinary e-learning system [1]. Generally, the aim of e-learning is to allow easy, free and searchable access to courses and to improve presentation of course materials and content in order to learn deeply and seriously. Unlike traditional learning and training, in such learning environment, individuals benefit from subjects on the basis of their own abilities. In elearning, maximum efficiency be obtained by combining and integrating various learning methods such as text, sound, phonemes, picture and etc [2].

Knowledge management and e-learning have common purposes. The aim is to improve individuals learning through training, sharing knowledge, and providing learner organization. Through convergence understanding, many attempts have been done in terms of proper integration. In this paper, we integrate these two fields (knowledge management and e-learning), and express their problems. Knowledge management can create a strong structure and framework for educational content and materials to support e- learning.

\section{VIRTUAL LEARNING (E- LEARNING) AND KNOWLEDGE MANAGEMENT}

Virtual learning is subset and common subject of information and learning technology. It provides learners continuous learning possibility everywhere and every time. In virtual learning, course presentation and learning is possible through new technologies. According to Davenport theory, knowledge management refers to a systematic process to find, select, organize and represent knowledge in a way that it increases individuals' abilities and capabilities in their area of interest [3].

In knowledge management, organizational view in terms of learning is considered, and it tries to recognize defects in terms of sharing knowledge among individuals of the organization.

\section{INTEGRATING LEARNING AND KNOWLEDGE MANAGEMENT}

Knowledge management and e-learning have common purposes. Their aims are to facilitate learning and to provide ability and specialty in an organization. Both 
technologies try to present effective knowledge in terms of information and data available in information resources of an organization. In addition, both of them try to improve performance and skills of individuals and groups by distributing knowledge in an organization. Hence, both technologies have a common strategy to create a learner organization. Another common aim of these technologies is the role of interaction, participation and group work of individuals in the organization.

In summary, the role and the effect of knowledge management on e-learning can be explained as follows:

In production cycle and knowledge management of an organization, knowledge can be changed to educational and learning content through using some techniques like grading, catalogue classification, adding the explanation and required interpretations, accommodation with the conditions of knowledge receiver, paying attention to learning and metadata to reuse it. Then, produced educational and learning content is enriched through applying standards, learning and training parameters, motivational parameters and more explanations. Later, a learning scenario is created, and it is presented to individuals, associations and cooperative learning groups. Knowledge presented in the form of learning is integrated with the experience and technical comments of individuals; then, it enters the cycle of knowledge management and elearning [6].

\section{THE PROBLEMS OF INTEGRATING VIRTUAL LEARNING AND KNOWLEDGE MANAGEMENT}

Studies and experiences have shown that many ideas presented in terms of integration of knowledge management and e-learning have not been applied and executed due to the following problems and limitations [5]:

* Conceptual level: lack of any conceptual and meaningful relationship between three spaces including work, knowledge and learning.

* Technical level: each above mentioned space involves different traditional and information systems, so integration of these systems is very difficult.

* Ignoring the field: the common problem of knowledge management and e- learning is that, in both of them, the field and conditions in which learning is provided and knowledge is transferred are considered differently. The way and the type of presenting learning and knowledge if different depending on environment conditions, background conditions, preparation, interests, talent and user information.

* Less interaction and cooperation: the problem of applying knowledge management in e- learning is that information parts in the system of knowledge management do not have enough relationship, cohesion, participation and cooperation. It should be considered that conceptual relationship and electronic have great importance in e- learning, and learner participation in learning process to increase learning percent is very important, while information has not been designed on the basis of participatory learning in knowledge management. In order to use information in learning process, learning participatory activities must be considered.

* The problem of dynamic conformity

* Inappropriateness of conceptual and applied content

\section{THE PLACE OF ELECTRONIC CONTENT IN E-LEARNING AT UNIVERSITY}

Generally, if we consider users (administration agents, teachers, students and supporting), learning processing (and their supporting services) and learning resources as the pillars of e- learning system, then communication and information technologies can be taken into account as an ability maker of this set. In one side, its duty is to provide communication bed and to manage required interactions among these pillars. On the other side, it can be considered as an element to enrich the content. On the basis of executive dimension, the activities of such structures can be divided into learning activities, and training and educational activities (such as administrative activities to support learning. Managing each of them requires special information systems.

With regard to integration approach of research0 learning in learning process at universities, three applications can be considered for learning resources:

1- Facilitation of achievement and reinforcement of information literacy

2- Facilitation of the process of transferring the main concepts and construction of knowledge in considered field.

3- Arranging a condition for being familiar with real world situation in considered field.

In information communities where people need information for their own professional, personal and recreational affairs, one of the main life skills is "information literacy" referring to a set of abilities through which it can be recognized that when and what kind of information is required, and in this way, required information can be evaluated and used effectively [7].

\section{VARIOUS APPROACHES OF LEARNING AND TRAINING}

There are three main methods of learning and training as follows: 
1- Instructional method: in this method, teacher and learning information are emphasized. The aim of this method is to transfer information from teacher to the student. This method is called parrot-like strategy.

2- Constructivist method: in this method, students (learners) are emphasized. Each person makes its own knowledge. In fact, the learner is responsible for its own learning. Teacher plays the role of leader and assistant in learning and training process. This method is called creative thinker strategy.

3- Social constructivist method: in this method, group study in interaction with a community (learning society) is considered with the aim of learning and obtaining knowledge. Learning this method is a process in the form of a social activity.

\section{DIFFERENT TYPES OF VIRTUAL LEARNING FOR USERS AND ADDRESSES}

Different kinds of this learning are as follows:

* Higher education: the users of this virtual learning are students, teachers, university staff and personnel and even the applicants of higher education courses. Concepts such as virtual and digital university are related to this kind of virtual learning.

* Training aid: the users of this virtual learning are students studying in various educational levels, their parents and teachers. Concepts like virtual schools, virtual high schools and etc. are related to this kind of virtual learning.

* General learning: the users of this virtual learning are ordinary and home users using information technology tools to increase individuals' skills.

* Personnel and staff training and learning: : the users of this virtual learning are personnel and staff of companies, institution, and private and general organizations. Using information technology in the field of education and training of manpower is usually offered to companies, factories and institution where there is much manpower [8]

* $\quad$ Ethics in virtual learning

The aim of ethics in information technology, e- learning and different kinds of it is to provide some tools to use and develop these systems by considering ethical dimensions. Ethics should be defined in the field of psychological knowledge [9] and the science based on respecting the rights of itself and others in interpersonal, intrapersonal and personal interactions [10].

Ethics in e- learning refers to patterns of communication behaviors based on respecting the rights of itself and others. It makes the ethical responsibilities of an organization clear. The rights of others mean internal and external elements of an organization. This organization has interpersonal and intrapersonal interactions. External environment cannot be just reduced to organization customers. Society, government, environment, neighbors and others are beneficiary of the organization [11]. If an organization has interaction in terms of profitability and presenting better services, then it can be considered as external environment. The elements of ethics in virtual learning have been demonstrated in figure 1 .

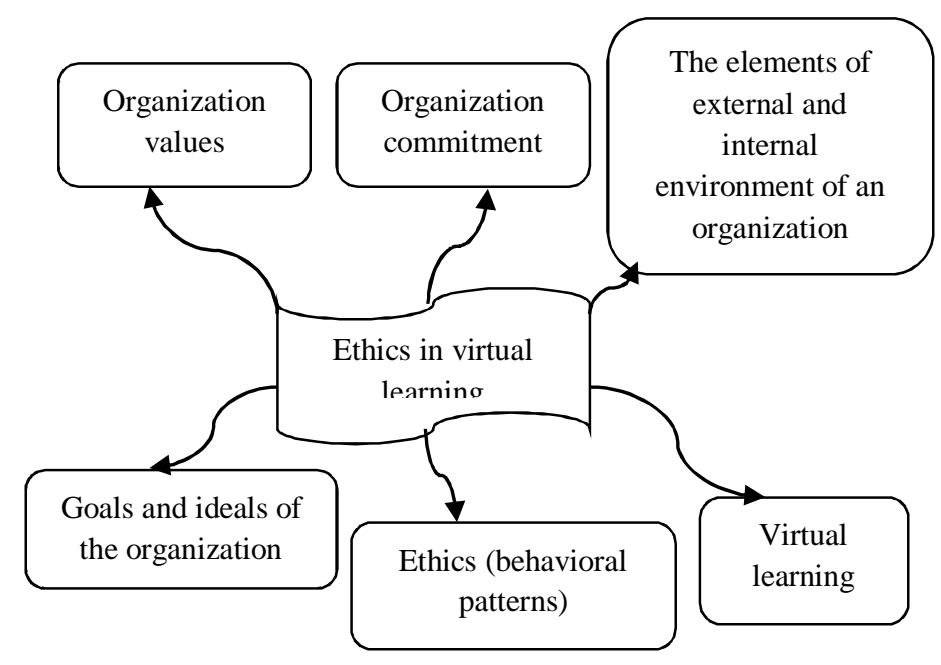

Figure 1: ethical components of virtual learning and training

\section{THE COMPONENTS OF VIRTUAL UNIVERSITY}

The components of virtual university are as follows:

* Information Booth: it helps students to understand virtual university, its services, its course syllabus and academic and degrees.

* Teaching unit: it refers to offices, and training and educational units presenting courses, seminars, laboratories, thesis and examination programs.

* Students' office: it is responsible of administrative and executive services such as recording courses, seminars, examinations and workshops.

* Digital library: through digital library, information lists of library can be accessed.

* Cafeteria: it provides students communication as well as discussion.

* Blackboard: students can be informed of news.

* Research center: this center informs students about research activities and publications. Also, it provides communication between students and researchers.

* Shop: this place facilitates buying course resources. 


\section{SOME CHARACTERISTICS OF VIRTUAL UNIVERSITY}

Virtual university refers to an environment presenting elearning services through using appropriate multimedia tools and communication structure. Some characteristics of virtual university are as follows:

* There is no need to physical presence of teacher and student in class.

* The higher quality of course syllabus

* Supporting many students in a class

* It is economical, and access is easy.

\section{CONCLUSION SUGGESTIONS}

AND

Understanding e-learning and knowledge management on the basis of their definitions is easy. These technologies can able the organization to manage their own knowledge capitals in production cycle of knowledge, training and learning content, and to transfer and share the content. Presenting training on the basis of business and knowledge requirements of staff and consistent with their interests and priorities has been considered by the organization in terms of integration of two concepts including e- learning and knowledge management. By integrating these technologies, learner organization using its own knowledge assets can be created. With regard to characteristics and capabilities of virtual environment and the role of virtual teacher in this environment, teacher encourages the students to cooperative learning. S/he participates in discussions as a mediator, and initiates discussion when necessary. Virtual teacher should design various learning activities, and should introduce reliable and valid resources to help and encourage students to participate actively in learning. Therefore, teaching strategies in course syllabus of virtual university must be selected according to the following instructions:

* They must increase the interaction between the teacher and student as well as their cooperation with each other.

* They must motivate the students to learn actively.

* They allow the teacher to pay attention to students by quick reaction.

* Individual differences of students must be considered.

* Cognitive flexibility should be reinforced in students.

* They must be selected on the basis of problemoriented methods and emphasizing on learning methods.

* They should facilitate the interaction between the learner and various resources of learning.

* Generally, the aim of training is to propagate ethics, but free communication in virtual learning and training, and emergence of unethical behaviors require paying attention to ethics. In discussion of ethics in virtual training, complete and exact conceptualization of this word is required. In conceptualization of ethics in virtual training, some factors have important place such as paying attention to ethics, virtual learning and training, the elements of internal and external organization environment, values, commitment and organizational goals and ideals because paying attention to just one dimension causes transition and change.

\section{REFERENCES}

[1] Standard institution and industrial researches of Iran, Elearning (Virtual Learning)- Characteristics. Tehran, 2010.

[2] Parinaz bani Si, Seddighe Mollaeian, Fatemeh Peikarifar. The first student conference of e- learning, science and industry university

[3] Okamoto Toshio, Ninomiya Toshie- Organization knowledge management system for e-learning practicein universities-IEEE Paper-Proceedings the sixth conference IASTED Interactional. Conference Web-Based Education, chamonix.France Year of Publication:2007- Volume2 -PP. 528- 536.

[4] Stefanie N. Lindstaedito.Johannes Farmer-integration Knowledge management and e-Learning. UCSS SpeciaI ls sue-Journal Universal Computer Science vol. 11. no.3 (2005)375-377submitted:3/3/05, accepted:17/3/05 appeared: 28/3/05 J .UCS-pp.375

[5] Ras Eric, Memmel Martin.Weibelzahl Stephan(Eds.)integration of E-Learning and Knowledge Management Barriers. Solution and Future lssues- Vol 3782/2005 -A thoff et al.( Eds.)WM 2005.L NAI 3782,2 005. SpringerVerlag Berlin Heidelberg 2005-K. D - pp. 155- 164.

[6] Miltiades D. Lytras, Ambjorn Naeve, Athanasius Pouloudi-Knowledge Management as a Reference Theory for ELearning:A Conceptual and Technological Perspective-Interactional Journal of Distance Education Technologies.3(2),1 -12,April- June2 005.Copyright@2005-pp.1-12.

[7] American Library Association. Presidential Committee on Information Literacy. Final Report.(Chicago: American Library Association, 1989.) 1 Information.

[8]Robabeh Farhady. E-learning as a New Paradigm in Communication Era. Periodical of science and information technology, pages 49-66, 2006.

[9] Nima Ghrbani. Communication Styles and Skills. Tehran: tenth punlication of Tabalvor, 2006.

[10] Faramarz Ghara Maleki. Professiobnal Ethics. Tehran, 2004

[11] Mohammad Mehr Mohammadi. Course syllabus, Perspectives and approaches. Tehran: Astane Ghodse Razavi, 2005. 